\title{
As dores do humano na sociedade midiática - um olhar sobre as relações entre suicídio e mídia
}

\author{
Regina Helena de Oliveira Santos NICOLOSI ${ }^{1}$ \\ Malena Segura CONTRERA ${ }^{2}$
}

\begin{abstract}
Resumo:
O suicídio é um fenômeno complexo e multifatorial, atravessado tanto por questões individuais quanto por referências sociais, culturais e históricas. A Organização Mundial de Saúde (OMS) aponta a ocorrência de cerca de 800.000 por ano, o equivalente a um suicídio a cada 40 segundos, o que o torna uma questão epidêmica e de saúde pública. Os jovens são os mais atingidos, principalmente os que estão na faixa dos 15 aos 24 anos. De acordo com o órgão, a mídia exerce papel fundamental tanto na prevenção quanto na disseminação do suicídio, pois este pode ser contagioso. O objetivo do artigo é analisar o fenômeno do suicídio - compreendido como fator social e refletir sobre o papel da mídia eletrônica nesse processo. A metodologia utilizada foi a revisão bibliográfica. A discussão, de base interdisciplinar, busca ferramentas teóricas nas áreas da Psicologia, Saúde Pública e Etologia para ampliar e compreender o que é próprio da prática comunicativa e em quais momentos os saberes se interpenetram em busca da ampliação da compreensão sobre as relações entre mídia e suicídio.
\end{abstract}

Palavras-chave: suicídio; sociedade midiática; sedação do corpo; contágio.

\section{The pains of the human in media society - a look at the relationship between suicide and the media}

\begin{abstract}
:
Suicide is a complex and multifactorial phenomenon, crossed by both individual issues and social, cultural and historical references. The World Health Organization (WHO) points to the occurrence of about 800.000 per year, the equivalent of one suicide every 40 seconds, which makes it an epidemic and public health issue. Young people are the hardest hit, especially those between 15 and 24 years old. According to the agency, the media plays a fundamental role both in preventing and spreading suicide, as it can be contagious. The objective of the article is to analyze the phenomenon of suicide - understood as a social factor - and to reflect on the role of electronic media in this process. The methodology used was the literature review. The interdisciplinary discussion seeks theoretical tools in the areas of Psychology, Public Health and Ethology to broaden and understand what is typical of communicative practice and at what times knowledge is interpenetrated in search of broadening the understanding of the relationships between media and suicide.
\end{abstract}

Keywords: suicide; media society; body sedation; contagion.

\footnotetext{
1 Doutoranda em Comunicação pela Universidade Paulista-UNIP. Bolsista CAPES-PROSUP. Mestre em Comunicação pela Universidade Paulista-UNIP, ORCID: https://orcid.org/0000-0002-0298-3712.

E-mail: reginanicolosi@gmail.com.

2 Doutora em Comunicação pela Pontifícia Universidade Católica de São Paulo (PUC/SP) e pós-doutora pela Universidade Federal do Rio de Janeiro (UFRJ), professora titular do PPGCOM de Comunicação e Cultura Midiática da Universidade Paulista. Líder do Grupo de Pesquisa em Mídia e Estudos do Imaginário e pesquisadora PQ do CNPq. ORCID http://orcid.org/0000-0003-4334-9467. E-mail: malenacontrera@uol.com.br.
} 


\title{
Los dolores del ser humano en la sociedad mediática: una mirada a la relación entre el suicidio y los medios
}

\begin{abstract}
Resumen:
El suicidio es un fenómeno complejo y multifactorial, atravesado tanto por cuestiones individuales como por referencias sociales, culturales e históricas. La Organización Mundial de la Salud (OMS) señala la ocurrencia de unos 800.000 por año, el equivalente a un suicidio cada 40 segundos, lo que la convierte en un problema de epidemia y salud pública. Los jóvenes son los más afectados, especialmente los que están en su grupo de edad de 15 a 24 años. Según la agencia, los medios de comunicación desempeñan un papel fundamental tanto en la prevención como en la difusión del suicidio, ya que puede ser considerado contagioso. El objetivo de este artículo es analizar el fenómeno del suicidio -entendido como un factor social- y reflexionar sobre el papel de los medios electrónicos en este proceso. La metodología utilizada fue la revisión de la literatura. El debate interdisciplinario, aunque se base centralmente em os estudio mediáticos, busca herramientas teóricas en las áreas de Psicología, Salud Pública y Etología para ampliar y entender lo que es apropiado para la práctica comunicativa y en qué momentos el conocimiento se interpenetra en busca de la expansión del entendimiento sobre las relaciones entre los medios de comunicación y el suicidio.
\end{abstract}

Palabras clave: suicidio; la sociedad de los medios de comunicación; sedación del cuerpo; contagio.

\section{Introdução}

O suicídio está presente desde o início da história humana e no decorrer do processo civilizatório suscitou as mais diversas interpretações e compreensões; as tentativas de compreendê-lo variaram e modificaram-se de acordo com a época e a cultura (MINOIS, 2018; DURKHEIM, 2000), mas, na sociedade midiática, ele adquire novos contornos que precisam ser considerados.

O objetivo deste artigo é refletir sobre as relações entre a onipresença da mídia eletrônica nas sociedades ocidentais contemporâneas e o aumento dos índices de suicídio em todo o mundo. A metodologia utilizada no trabalho foi a de revisão bibliográfica e análise de dados sobre a crescente presença dos meios de comunicação eletrônicos e os índices de suicídio apresentados pela OMS. A discussão contou com autores como Émile Durkheim (2000), George Minois (2018), Neury José Botega (2015), Norval Baitello Júnior (2005, 2010, 2012) e David Le Breton (2003), entre outros.

\section{O suicídio é humano}

Em uma breve linha do tempo, torna-se evidente a diversidade de interpretações que o suicídio recebeu no decorrer do processo civilizatório. Minois (2018) aponta que para certos povos primitivos, por exemplo, o suicídio era uma necessidade altruísta para a sobrevivência 
da tribo, e foi somente na Antiguidade Clássica que se começou a problematizar e interpretar a morte voluntária, perguntando-se por suas causas. Os mitos gregos estão repletos de heróis e heroínas que tiram a própria vida por motivos aparentemente justificáveis (GUIMARÃES, 2010; MINOIS, 2018). Ainda na Antiguidade greco-romana, o suicídio era considerado uma opção, um ato de liberdade, e algumas cidades gregas tinham certo estoque de veneno para fornecer aos cidadãos que quisessem se matar (BOTEGA, 2015).

Foi o desenvolvimento das religiões que problematizou o suicídio, e cada religião definiu seus interditos e regras sobre ele. As religiões abraâmicas, onde a vida é uma dádiva divina inalienável, condenaram os suicidas, com exceção dos mártires e daqueles que se sacrificavam pelo bem comum. No entanto, na maioria dos casos, essa matriz religiosa previu punição tanto para a família quanto para o morto, ao negar o enterro do corpo em solo sagrado e sem os devidos rituais funerários (SAMPAIO, 2002).

$\mathrm{Na}$ Roma clássica, por exemplo, o suicídio era visto de modo neutro ou mesmo positivo, mas no século IV a posição radical de Santo Agostino, ao rejeitar o suicídio, veio modificar profundamente o modo de encarar. No século XIII, S. Tomás de Aquino retoma a ideia do suicídio-pecado, ao afirmar que só Deus tem o direito a dar e a tirar a vida, posição que caracteriza o período medieval (SAMPAIO, 2002, p. 22-23).

$\mathrm{O}$ autor menciona que o entendimento do ato como sacrilégio "influenciou as comunidades durante muitos anos e levou a que muitos fossem criticados e mesmo perseguidos pelo facto de terem atentado contra a própria vida" (SAMPAIO, 2002, p.23). Na Europa medieval compreendia-se o ato como um assassinato, a lei exigia a execução do cadáver do assassino e que pesadas multas fossem aplicadas sobre o espólio do suicida (BOTEGA, 2015; MINOIS, 2018). Minois (2018) descreve diversas situações curiosas sobre esse período histórico, como a ocorrida em Reims (França), no ano de 1278, quando um homem tirou a própria vida. Em seguida, “os religiosos de Saint-Remi mandam arrastar e enforcar o corpo; mas o Parlamento de Paris os condena a restituir o cadáver à jurisdição do arcebispo, o único que tem o direito de enforcar (MINOIS, 2018, p.8) Com o passar do tempo e o aparecimento 
do Iluminismo e do Romantismo europeu, o ato de tirar a própria vida passou a ser visto como um dilema da consciência e da ciência (BOTEGA, 2015; MINOIS, 2018).

Apenas no final do XVII surge o termo "suicídio", no livro de Sir Thomas Browne (1605-1682), denominado Religio Médici (1642). Em 1656, o teólogo Juan Caramuel y Lobkowitz (1606-1682) o coloca em seu tratado de Theologia moralis fundamentalis. Posteriormente, em 1734, o abade René Louiche Desfontaines (1750-1831) utilizou a palavra para definir "o assassinato ou a morte de si mesmo" (MELEIRO; MELLO-SANTOS; WANG, 2007, p. 475). O Dictionnaire de 1762 foi o primeiro a ter um verbete para "suicídio", palavra derivada do latim e que etimologicamente significa "sui" (si mesmo) e "caedes" ("ação de matar", "morte violenta, imolação") (MELEIRO; MELLO-SANTOS; WANG, 2007, p. 475; GUIMARÃES, 2010, p. 4). O sentido de imolação ainda evoca a relação religiosa que poderia ligar o tema do suicídio ao do sacrifício (MINOIS, 2018). Mas essa relação entre suicídio e sagrado foi sendo cada vez mais apagada, de modo a praticamente não ser considerada atualmente.

No século XVIII, Jean-Jacques Rousseau discutiu o suicídio sob o enfoque da "condição natural do homem, considerando que é a sociedade que o torna mau e criminoso, ao chamar a atenção para as condições sociais da existência humana" (SAMPAIO, 2002, p. 23).

No final do século XIX, Émile Durkheim (1858-1917) analisou o suicídio de forma inédita e, a partir de então, também se passa a considerar o suicídio como uma questão social, definindo-o como "todo o caso de morte que resulta, direta ou indiretamente, de um ato, positivo ou negativo, executado pela própria vítima, e que ela sabia que deveria produzir esse resultado" (DURKHEIM, 2000, p.14). Durkheim propõe que o olhar sobre o fenômeno deve ser mais amplo que apenas o psicológico ou biológico, pois a sociedade não existe sem o indivíduo, nem o indivíduo sem sua condição social.

Durkheim (2000) apontou para quatro tipos de suicídio: egoísta, altruísta, anômico e fatalista, divididos em duas categorias: a primeira diz respeito à qualidade da integração social na qual se enquadram tanto o "suicídio egoísta", referente à desconexão social e a uma percepção de não pertencimento, quanto o "suicídio altruísta", relativo ao senso de dever para com determinado grupo. A segunda categoria está ligada à identificação com o grupo e à pressão social exercida sobre o indivíduo. Temos nessa categoria o "suicídio anômico", ligado à 
dissociação social oriunda de distúrbios sociais e econômicos, e o "suicídio fatalista", que é resultado do excesso de disciplina e de regulação da sociedade e opressão dos desejos individuais.

No século $\mathrm{XX}$, outras áreas do conhecimento humano continuaram a pensar e a pesquisar o tema sob as mais diversas perspectivas e Albert Camus, no ensaio O mito de Sísifo, publicado em 1944, aproximou o tema do leitor não especialista, apresentando a relação do suicídio com a falta de sentido da condição humana: "Só há um problema filosófico verdadeiramente sério: é o suicídio. Julgar se a vida merece ou não ser vivida, é responder a uma questão fundamental de filosofia" (CAMUS, 2019, p. 8).

Camus exclui o fator social, contrapondo-se ao pensamento de Durkheim (2000), que entendia o suicídio como algo inerente às questões coletivas. Ao afirmar que "O verme se acha no coração do homem" (DURKHEIM, 2000, p. 9), propõe uma busca interna para as questões da morte voluntária. Na época, observou a forma com a qual a mídia relatava e retrava o suicídio e os motivos que levavam as pessoas a tirarem as próprias vidas, afirmando que os jornais falavam frequentemente de "profundos desgostos" ou de "doença incurável", considerando que "essas explicações são válidas" (DURKHEIM, 2000, p. 9), o que faria "precipitar todos os rancores e todos os aborrecimentos ainda em suspensão" (DURKHEIM, 2000, p. 9).

Na década de 1960, pela primeira vez um órgão como a Organização Mundial de Saúde (OMS) chamou a atenção para esse comportamento e, diante do aumento rápido e exacerbado de casos, em 1990, o órgão passou a considerar o suicídio como um grave problema de saúde pública (BOTEGA, 2015).

De acordo com pesquisa realizada pela OMS, publicada pela primeira vez em 2014 e atualizada em 2019, o suicídio está entre "as vinte principais causas de morte em todo o mundo, com mais mortes por suicídio do que por malária, câncer de mama ou guerra e homicídio" (WORLD HEALTH ORGANIZATION, 2019, p. 7, tradução nossa). ${ }^{3}$ De acordo com a OMS, uma pessoa se mata a cada 40 segundos (SUICIDE..., 2019). ${ }^{4}$ Ao chegarmos ao século XXI,

\footnotetext{
3 "It is among the top twenty leading causes of death worldwide, with more deaths due to suicide than to malaria, breast cancer, or war and homicide" (WORLD HEALTH ORGANIZATION, 2019, p. 7).

${ }^{4}$ Decidimos não considerar os dados de 2020 por entendermos que se tratou de um ano de radical exceção, e os dados desse ano poderiam maquiar os resultados.
} 
pela dimensão do problema que atinge todos os países do mundo, o suicídio é considerado, além de uma questão de saúde pública, uma verdadeira pandemia.

Posteriormente, a pesquisa realizada pela OMS gerou a publicação Prevenção do suicídio: um manual para profissionais da mídia (ORGANIZAÇÃO MUNDIAL DA SAÚDE, 2000). O texto ressalta que uma das relações diretas entre mídia e a propagação de casos de suicídio é a forma como a qual as informações são tratadas.

O suicídio é talvez a forma mais trágica de alguém terminar a vida. A maioria das pessoas que consideram a possibilidade de cometer o suicídio são ambivalentes. Elas não estão certas se querem realmente morrer. Um dos muitos fatores que podem levar um indivíduo vulnerável a efetivamente tirar sua vida pode ser a publicidade sobre os suicídios. A maneira como os meios de comunicação trata casos públicos de suicídio pode influenciar a ocorrência de outros suicídios (ORGANIZAÇÃO MUNDIAL DA SAÚDE, 2000, p. 3).

A possibilidade de imitação do comportamento suicida, quando "um suicida exerce um efeito modelador em suicídios subsequentes" (ORGANIZAÇÃO MUNDIAL DA SAÚDE, 2000 , p. 3), depende muito da forma, intensidade e detalhamento que as informações são transmitidas. Quando tais fenômenos ocorrem em forma de agrupamentos ou em quantidade anômala de suicídios ocorridos "em estreita proximidade temporal e/ou geográfica, com ou sem qualquer ligação direta”, são denominados clusters (ORGANIZAÇÃO MUNDIAL DA SAÚDE, 2000, p.3)-

A questão de como a mídia funciona como uma grande referência geradora de padrões miméticos já foi estudada por Contrera $(2012,2017)$ e por isso não nos ateremos aqui a esse ponto, mas valeria lembrar a potência da criação de padrões miméticos já atestada a partir da experiência literária de ficção (ORTIZ; KHIN KHIN, 2018).

Também Torres (2020), ao tratar da questão dos processos de contágio psíquicos na sociedade mediática, ajuda-nos a compreender essa relação entre mídia e contágio psíquico das massas no cenário da atual sociedade em rede. 


\section{A mídia e o suicídio}

A primeira relação entre mídia e suicídio que gerou forte impacto social ocorreu por meio da mídia impressa ainda no século XVIII (ORGANIZAÇÃO MUNDIAL DA SAÚDE, 2000). Em 1774, Johann Wolfgang von Goethe (1749-1832) publicou a obra Os sofrimentos do jovem Werther (Die Leiden des Jungen Werther), livro no qual o protagonista da trama perde sua amada para outro homem e, desesperado por não ter seu amor correspondido, se mata com um tiro, mas não sem antes deixar uma carta explicando os motivos de sua escolha. $\mathrm{O}$ fenômeno que se seguiu foi denominado “efeito Werther" (ORGANIZAÇÃO MUNDIAL DA SAÚDE, 2000; DAPIEVE, 2006; BOTEGA, 2015; MINOIS, 2018) e consistiu em uma onda de suicídios na Europa que mimetizavam os passos trágicos do herói. Na época, muitos jovens acabaram com a vida com um tiro de pistola, e "exemplares do livro de Goethe eram achados ao lado dos moribundos ou dos cadáveres" (DAPIEVE, 2006, p. 12). Devido ao grande número de suicídios associados à história e para impedir o contágio e a disseminação da onda mortal, muitos países europeus proibiram a publicação do livro (ORGANIZAÇÃO MUNDIAL DA SAÚDE, 2000).

No entanto, a mídia eletrônica e seus atravessamentos no cotidiano do homem a partir do século XX trouxe uma nova dimensão a essa relação entre mídia e suicídio (ORGANIZAÇÃO MUNDIAL DA SAÚDE, 2000), que não passa apenas pelas práticas miméticas ou de sugestão, mas, sim, pelas condições de sociabilidade do homem da sociedade midiática. Nas primeiras duas décadas do século XXI essa associação parece mais intensa, já que a descoberta e o desenvolvimento das novas tecnologias e a disseminação dos aparatos eletrônicos trouxeram consigo novas possibilidades do uso da mídia (CONTRERA, 2012), inclusive algumas relacionadas ao suicídio, o que tem sido estudado sob diferentes aspectos. Um desses aspectos é o papel direto da mídia no denominado cyberbullying, quando há a disseminação de conteúdo nocivo à vítima como fotos, vídeos, mensagens, memes. Aqui a mídia eletrônica opera como gatilho e amplificadora do comportamento suicida até mesmo por meio de manual de instrução sobre formas de tirar a própria vida (BARRETO JR.; LIMA, 2017).

O impacto na vida de pessoas vítimas de cyberbullying foi, por exemplo, analisado por Sacramento (2016) a partir das narrativas de celebridades apresentadas em programa de TV, evidenciando o quanto é recorrente a exposição de sofrimentos íntimos e traumas na mídia 
eletrônica, e de que modo a "exposição e, mais particularmente, a autoexposição de traumas tornaram-se elementos cruciais da cultura da mídia recente" (SACRAMENTO, 2016, p. 150).

Mas um fenômeno em específico tem sido observado com frequência e considerado uma patologia recente. A adição relacionada ao excesso de Internet e sua associação com o suicídio tem aumentado ano a ano, afetando principalmente o público juvenil (LIN, I-Hsuan; KO; CHANG; LIU; WANG; LIN, Huang-Chi; HUANG; YEH; CHOU; YEN, 2014; KATO; SHINFUKU; TATENO, 2020; RYU; CHOI; SEO; NAM, 2004). A correlação entre a dependência de Internet, a depressão e a ideação suicida foi evidenciada em pesquisa de Ryu, Choi, Seo e Nam (2004) sobre adolescentes. Na conclusão, apontam para a necessidade da atuação mais atenta e consciente dos profissionais de saúde nas escolas, por ser ela o primeiro local para identificação do fenômeno.

Também Siebel, Santos, B. S., Moreira e Santos, V.S. (2019) avaliaram o impacto das redes sociais no comportamento suicida em adolescentes, evidenciando que questões relacionadas à necessidade de pertencimento, a impulsividade, a falta de conhecimento e preparo, tanto dos familiares, quanto da escola e da comunidade, são fatores predisponentes para o suicídio. Para frear e prevenir tais comportamentos são sugeridas ações como terapias, palestras e dinâmicas de grupo que tratem de temas como autoestima, bullying, orientação sexual e suicídio, entre outros.

O artigo de Popoola, Olagundoye e Alugo (2020) descreve as mídias sociais como fator de alto impacto na vida e nas habilidades sociais dos indivíduos, enraizada em todas as áreas da vida humana, mas principalmente dos adolescentes. E aponta a correlação entre o aumento do uso das mídias sociais e o crescimento das taxas de suicídio. Ferreira, Oliveira, Medeiros, Gomes, Cezar-Vaz e Ávila (2020), do mesmo modo, ressaltam o impacto na saúde biopsicossocial de adolescentes em sua relação com a Internet. Como podemos notar, o tema de fato tem mobilizado pesquisadores em busca de avaliar a dimensão de seu impacto.

Também deve ser considerado o fato de que alguns usuários passaram a usar as redes sociais para transmissões ao vivo de seus suicídios, levando ao paroxismo o diagnóstico de Debord (1997) acerca da espetacularização da vida. Pereira e Botti (2017) alertam para a vulnerabilidade dos jovens frente aos conteúdos on-line que estimulem o suicídio, além da fácil acessibilidade à mídia digital. Reforçam também a necessidade de maior visibilidade dos 
conteúdos de prevenção ao suicídio nos meios digitais, sobretudo frente a conteúdos propriamente inerentes à adolescência, sendo assim de extrema importância aumentar a visibilidade das campanhas de prevenção.

A forma pela qual a mídia divulga os casos pode levar tanto à busca por ajuda como estimular o aumento de ocorrências (COSTA, 2014). O suicídio de celebridades como o músico Kurt Corbain (CANZIAN, 1994) e o ator Robin Williams ${ }^{5}$ (SUICÍDIOS... 2018), por exemplo, aparentemente estimularam outros atos semelhantes, ou, no melhor dos casos, mais pedidos de ajuda. Almeida (2000) lembra que a morte do músico desencadeou imediatamente um grande aumento de telefonemas suicidas nas centrais de ajuda. Já após o suicídio de Robin Williams, os casos de tentativas e de morte por suicídio se intensificaram.

Vale ressaltar que falar do suicídio, informar as pessoas para seus riscos e quais os sinais de alerta mais comuns não aumenta o número de casos. Campanhas de prevenção e informação corretas só previnem o suicídio, o que aumenta os índices é a forma como a mídia aborda o tema. Quando esta apresenta o suicida no papel de herói ou mesmo mártir - e temos de considerar que uma cultura cristã desde sempre associa o martírio ao heroísmo - pode acabar incentivando outras pessoas emocionalmente instáveis e deprimidas, como já visto desde o "efeito Werther". Acreditamos que, se levarmos ainda em consideração que os índices de depressão também subiram vertiginosamente, compreendemos quão delicada é essa situação.

Romano (2004) propõe uma reflexão acerca da Ecologia da Comunicação, inspirado na teoria da mídia de Harry Pross (BETH; PROSS, 1990), na qual ressalta as implicações de termos optado por meios de comunicação que se ocupam exclusivamente da comunicação à distância (auditiva e visual) e termos frequentemente negligenciado a comunicação dos sentidos da proximidade (tato, paladar, olfato, somatossensorial). Romano, bem como Berman (2007), ao falar da Modernidade, insiste na importância da alteração das relações de espaço-tempo vivenciadas pelo homem, que passa a se adaptar a um ritmo e a novas formas de relação com o ambiente imediato que o afastam cada vez mais dos ritmos biológicos e o retira das vivências que antes o inseriam numa dimensão ecológica da vida mais abrangente. Consequentemente, o

\footnotetext{
5 A reportagem com o título "Suicídios aumentaram nos EUA logo após Robin Williams se matar, mostra levantamento" (2018) se baseia em um estudo publicado na revista científica PLOS One, que comprovou um aumento de 10\% nos casos de suicídio nos EUA em 2014 após a morte do ator Robin Williams.
} 
homem da sociedade midiática perde crescentemente o pouco que tinha de autonomia existencial quando se distancia dos afazeres e da dimensão do concreto.

Claramente essa opção pelo audiovisual teve motivações econômicas, como bem pontua Morin (2018) ao apresentar sua reflexão acerca da cultura de massas, considerando ainda o protagonismo dos meios de comunicação nesse cenário. É de extremo valor sua percepção de que à industrialização dos meios de produção seguiu-se uma necessária industrialização do espírito, para tornar possível uma sociedade do consumo que fizesse triunfar o valor supremo do capital.

Novas formas de mídia foram desenvolvidas no século XX e revolucionaram tanto a comunicação quanto as formas de interação entre as pessoas. Isso, que parece ter sido muito bom do ponto de vista da ampliação dos mercados econômicos e da intensificação das práticas de consumo, gerou, em contraponto, toda uma nova condição do homem no mundo, e, sobretudo, do homem com outros homens, influindo pesadamente sobre as formas de sociabilidade (CONTRERA, 2017; ORTIZ; KHIN KHIN, 2018). Um desses efeitos - e o que mais nos interessa analisar para a reflexão que propomos - é a obsolescência do corpo e a substituição do vínculo cultural vivencial pelo vínculo hipnógeno, como veremos adiante.

Esse movimento de redução das vivências concretas, que atinge um grau extremo contemporaneamente, começou, no entanto, há muito tempo. Baitello Júnior (2010) fala, a partir de Vilém Flusser, acerca de como essa escalada da abstração incide sobre a condição contemporânea do homem da sociedade midiática, evidenciando a perda das dimensões espaçotemporais ocorrida nesse processo. À hominização segue-se a sedentarização, até termos o momento atual, a terceira catástrofe, ainda não nomeada, quando o homem volta a ser nômade, mas não é seu corpo que se move, “[...] sua casa fica inabitável, porque por todos os seus buracos entra o vento da informação (com suas imagens técnicas, transmitidas pelas tomadas de eletricidade). Este o conduz a um nomadismo de novo tipo, no qual não é mais o corpo que viaja, navega ou caminha, mas o seu espírito [...]” (BAITELLO JÚNIOR, 2006, p. 3).

As funções de acolhimento e proteção da casa se diluem frente à intensidade e à violência dos ventos da informação que chegam pelos meios, tornando a casa inabitável, como aponta Baitello Júnior (2012). Assim como a casa é permeável, nosso corpo também sofre influências do que o autor denomina "furacão da mídia” (BAITELLO JÚNIOR, 2012, p. 28). 
O fenômeno da saturação da informação (CONTRERA, 2017) e a Síndrome de Burnout associada a ela já foram bem explorados (SERVA, 2019). Também o sentimento de constante déficit sentido pelo homem dos centros urbanos contemporâneo e como isso pode intensificar os quadros de ansiedade já foram discutidos, mas pouco se falou de consequências radicais, tais como o suicídio, decorrentes desse processo de abstração do corpo humano.

No caso do corpo, essa escalada da abstração nos transformou em nômades sem corpo, pois ele não parece mais necessário, tornando-se obsoleto (BAUDRILLARD, 1991). Baitello Júnior (2012) descreve o esforço que o corpo faz ao ficar artificialmente sentado, fraturado, fincado em base estática; tal postura desliga o homem de suas raízes da inteligência primata e do nômade, colocando-o num estado perene de sedação. $\mathrm{O}$ imenso e terrível vazio que resta tentamos preencher de forma fortuita e insuficiente por meio do crescente consumo de imagens técnicas (BAITELLO JÚNIOR, 2005), mas acabamos devorados pelas imagens que desesperadamente buscamos devorar.

Le Breton, em sua obra Adeus ao corpo (2003), reflete sobre as consequências desse processo de desmaterialização do corpo e apresenta uma série de consequências e impactos decorrentes desse processo, tanto no âmbito individual, quanto social. No entanto, muito pouco se falou sobre como esse distanciamento do corpo já abriga em seu próprio âmago a ideia de suicídio.

\section{Ninguém escapa aos limites da própria pele}

Cyrulnik (1999, p. 103), ao estudar uma etologia dos afetos humanos, afirma que "todos os organismos são porosos, mesmo ao nível biológico elementar, é a troca com o mundo exterior que lhes permitem viverem, desenvolverem-se, tentarem ser eles mesmos". Em sua proposta de uma "biologia do ligante" (CYRULNIK, 1999, p. 92), ele ressalta o protagonismo dos sentidos nas interações do homem com o mundo, e na centralidade dessas interações para a constituição tanto da própria identidade como o sentimento de pertença.

Somos permeáveis ao mundo e, consequentemente, a tudo que nos atravessa. Esses estímulos, que são múltiplos e vindos de diferentes registros sensoriais, se restringem a dois sentidos - visão e audição -, como se dá atualmente com a onipresença da mídia eletrônica nas mediações de todo tipo, que, por meio das imagens técnicas com as quais se constrói o hiper- 
real, simula uma realidade. Tal realidade é aparentemente melhor, mais colorida e vibrante, e sobretudo mais adaptada aos desejos e conveniências de um homem cada vez mais infantilizado pela falta de vivências concretas. Nesse cenário, o corpo se reduz ao mínimo de percepção de domínio espaço-temporal necessários. A sociedade digital aposta tudo na redução da ação do corpo à ação das pontas dos dedos (dígitos) (CONTRERA, 2012, 2017).

A comunicação virtual recria pontes virtuais que parecem reais para atingir o outro, e, ansiosos pelo outro, caímos no deserto das conexões via aparatos eletrônicos e rede de computadores, nas quais encontramos quase sempre grandes vazios, muito lucrativos, aliás, para a sobrevivência da sociedade do consumo. O corpo perde sua propriocepção e a sedação dos sentidos leva ao rebaixamento da consciência, já que o corpo perde seu protagonismo nas formas de apropriação do espaço-tempo a partir do qual se constrói a própria percepção de se estar vivo (CONTRERA, 2012; BAITELLO JÚNIOR, 2012).

A propriocepção foi definida no começo do século XX por Sherington primordialmente como a capacidade de reconhecimento postural das partes do corpo no espaço (ANTUNHA, 2008). Como parte do sistema denominado somatossensorial, integra "todas as informações mecânicas, originadas pelos mecanorreceptores, dolorosas, originadas pelos nocirreceptores e térmicas, originadas pelos termorreceptores" (LEPORACE, 2009, p. 127). O processo proprioceptivo ou cinestesia ocorre quando o cérebro recebe informações sobre o posicionamento das articulações por duas vias, uma consciente, outra não. A operação proprioceptiva é base para a construção da autoimagem e do esquema corporal. Sem a propriocepção, o corpo sofre o declínio dos outros sentidos, como o tato, o paladar e o olfato, e a visão, por sua vez, fica sobrecarregada, gerando uma nova forma de cegueira e surdez, referida pelo "padecimento dos olhos", que Kamper (1994) menciona, ou ainda pelo Ensaio sobre a cegueira, de Saramago (1995).

Esse rebaixamento da consciência, somado à atenção focada (CARR, 2011), gera um estado no qual deixamos de nos vincular ao outro de forma real, por meio do que se pode entender como vínculo gerado em um contexto de imersão cultural. Afirmam Silva e Baitello Júnior (2013, p. 6):

Vínculos comunicacionais, portanto, podem ser divididos em dois grupos. O primeiro grupo, o dos vínculos culturais, estabelece-se no contexto histórico- 
antropológico, fundado na densidade vivencial e na tessitura simbólica, na dupla implicação entre aqueles que se comunicam, que comungam uma mesma atmosfera simbólica. O segundo grupo, o dos vínculos hipnóticos, estabelece-se no contexto midiático (mediosfera), fundado na construção de imagens técnicas fugazes que obedecem cegamente aos programas, dentre eles o programa cristalizado dos papéis de emissor e receptor. Caracteriza-se este último pela ludicidade exacerbada (cega e obediente), isto é, pela finalidade em si mesma e pela ilusão (in ludere), por parte do receptor, de que ao agir sobre o aparelho atua como emissor.

Passamos a criar uma rede de apoio com conexões instrumentais; para isso, utilizamos os aparatos como computadores e celulares conectados em redes. Buscamos a vinculação real, mas estamos presos em vínculos hipnógenos (SILVA; BAITELLO JÚNIOR, 2013).

Vínculos hipnóticos/hipnógenos caracterizam-se não somente pela resposta literal ao comando estabelecido, mas também por esta ação basear-se em forte poder de comando do hipnotizador para com o hipnotizado. Sua natureza, entretanto, é a instituição instantânea (ação arrebatadora), a obsolescência e a efemeridade (não perduram no tempo) e a superficialidade ou gratuidade (pretendem sempre ser autossuficientes e autorreferentes, se apresentam como inócuos e inofensivos). Podemos considerar que se diferenciam por completo dos vínculos fundados em ambientes da cultura em sua dimensão históricoantropológica (SILVA; BAITELLO JÚNIOR, 2013, p. 6).

O vínculo pressupõe uma conexão afetiva e emocional que passa pelo corpo. Sem a propriocepção corporal, hipnotizados pelas conexões técnicas instrumentais e ligados a aparatos eletrônicos por pontes virtuais, restam a solidão e o desejo exacerbado de pertencimento. A consciência dá conta, ao chegar a esse ponto, apenas da dor, e essa existência fantasmagórica anseia que a dor finde. Nesse contexto, acreditamos que a ideação suicida pode surgir como o alívio para tal sofrimento.

\section{Considerações finais}

O processo civilizatório e a conquista da técnica culminaram no surgimento de tecnologias que o homem utiliza para interagir com o mundo e agir sobre ele. Mas as tecnologias da comunicação foram sempre vendidas por meio de uma crença, implantada com bastante eficácia, acerca da superioridade e praticidade da mediação eletrônica. Toda a produção audiovisual foi suficientemente glamourizada para que não víssemos as contraindicações que ela abrigava desde o início. Recentemente, em 2020, O dilema das redes - um documentário 
que trata dos riscos humanos e sociais do domínio da comunicação eletrônica - tem causado bastante surpresa junto aos não especialistas, mas os efeitos da presença absoluta do ambiente eletrônico nas relações humanas não é novidade para quem tem estudado teoria da mídia e olhado para os seres humanos, e não apenas para os aparatos técnicos e para seus códigos.

Entre essas contraindicações - que já vêm sido investigadas há aproximadamente uns trinta anos com muita clareza aqui no Brasil, basta olharmos para a contribuição, por exemplo, do pensamento de Muniz Sodré, de Norval Baitello Júnior, de Ciro Marcondes Filho, entre outros autores - propomos agora olhar para a relação entre a mídia eletrônica, a sedação do corpo e o aumento do sofrimento psíquico por trás dos índices de suicídio, que só crescem no mundo.

O apagamento do corpo, como alerta Le Breton (2003), lança um novo olhar sobre esse ato de tirar a própria vida. O suicídio, que acompanha a humanidade desde os seus primórdios, é, de certa forma, estimulado pela mídia eletrônica, mas não necessariamente como um assunto, e, sim, como um procedimento. O corpo busca o vínculo, mas é capturado pelos estímulos audiovisuais da tela que absorve seu tempo de vida, sua atenção, enfim, sua energia. Dessa forma, o suicídio não ocorre em um único gesto, ele está presente todo o tempo, se considerarmos o estado anestésico do corpo acoplado às telas cada vez mais horas por dia, principalmente se levarmos em conta o crescimento dos índices do tempo em que o brasileiro passa na Internet e que encontra nos jovens seus maiores índices (KEMP, 2020).

O fato de a faixa etária dos maiores usuários de mídia eletrônica ser também a mesma faixa na qual o suicídio mais cresce não é mera coincidência, como aqui propomos. Ao menos, temos aqui uma relação que precisa ser discutida, e essa discussão só poderá se dar de forma interdisciplinar entre as áreas de Comunicação, Psicologia e Saúde Pública.

Considerar o padecimento dos corpos no contexto da sociedade midiática passa por reconhecer que o corpo anseia viver - o imperativo biológico dos seres vivos -, mas o estado de sedação só faz aumentar a impotência e a fragilidade do ego, frente ao qual a solidão, a angústia, a incapacidade de pertencer e o vácuo desértico da conexão técnica instauram um vazio de sentido e um sentimento de abandono que geram um ambiente social e afetivo no qual o suicídio só cresce. Sedado, fragilizado e só, em algum momento o homem contemporâneo parece buscar no suicídio o fim de seu sofrimento. 


\section{Referências}

ALMEIDA, Ana Filipa. Efeito de Werther. Análise psicológica, Lisboa, v. 18, n. 1, p. 37-51, 2000 .

ANTUNHA, Elsa Lima Gonçalves; SAMPAIO, Paulo. Propriocepção: um conceito de vanguarda na área diagnóstica e terapêutica. Bol. - Acad. Paul. Psicol., São Paulo, v. 28, n. 2, p. 278-283, dez. 2008.

BAITELLO JÚNIOR, Norval. A era da iconofagia: ensaios de comunicação e cultura. São Paulo: Hacker ed., 2005.

BAITELLO JÚNIOR, Norval. Vilém Flusser e a terceira catástrofe do homem ou as dores do espaço, a fotografia e o vento. Flusser Studies, v. 3, p. 1-7, Nov. 2006. [Special Brazilian Issue]. Disponível em:

https://flusserstudies.net/sites/www.flusserstudies.net/files/media/attachments/terceiracatastrofe-homem.pdf. Acesso em: 15 ago. 2020.

BAITELLO JÚNIOR, Norval. A serpente, a maçã e o holograma: esboços para uma teoria da mídia. São Paulo: Paulus, 2010.

BAITELLO JÚNIOR, Norval. O pensamento sentado: sobre glúteos, cadeiras e imagens. Editora Unisinos, 2012.

BARRETO JÚNIOR, Irineu Francisco; LIMA, Marco Antonio. Suicídio e o jogo da baleia azul analisados na perspectiva de Émile Durkheim. Revista de Sociologia, Antropologia e Cultura Jurídica, Brasília, v. 3, n. 1, p. 121-136, 2017.

BAUDRILLARD, Jean. Simulacros e simulação. Lisboa: Relógio d'Água. 1991.

BERMAN, Marshall. Tudo que é sólido desmancha no ar. São Paulo: Companhia das Letras, 2007.

BETH, Hanno; PROSS, Harry. Introducción a la ciencia de la comunicación. Barcelona: Anthropos Editorial, 1990. 
BOTEGA, Neury José. Crise suicida. São Paulo: Artmed, 2015.

CAMUS, Albert. O mito de Sísifo. Rio de Janeiro: Record, 2019.

CANZIAN, Fernando. Líder do Nirvana se mata aos 27. Folha de S. Paulo, São Paulo, 9 abr. 1994. Disponível em: https://www1.folha.uol.com.br/fsp/1994/4/09/cotidiano/1.html_.Acesso em: 15 ago. 2020.

CARR, Nicholas. O que a Internet está fazendo com os nossos cérebros: a geração superficial. Rio de Janeiro: Agir, 2011.

CONTRERA, Malena Segura. Mediosfera: meios, imaginário e desencantamento do mundo. Porto Alegre: Imaginalis, 2017.

CONTRERA, Malena Segura. Mimese e mídia: novas formas de mimese ou uma consciência hipnógena. In: BORNHAUSEN, Diogo Andrade; MIKLOS, Jorge; SILVA, Maurício Ribeiro da (org.). CISC 20 anos: Comunicação, cultura e mídia. São José do Rio Preto, SP: Bluecom Comunicação, 2012. p. 411-425.

COSTA. Ana Luisa. A relação entre o suicídio e a internet: o fenômeno do 'suicídio. com'. In: CONGRESSO DE CIÊNCIAS DA COMUNICAÇÃO NA REGIÃO SUDESTE, 19., 2014, Vila Velha, ES. Anais [...]. São Paulo: Intercom, 2014.

CYRULNIK. B. Do sexto sentido. Lisboa: Instituto Piaget, 1999.

DAPIEVE, Arthur Henrique Motta. Suicídio por contágio: a maneira pela qual a imprensa trata a morte voluntária. 2006. Dissertação (Programa de Pós-Graduação em Comunicação Social) - Departamento de Comunicação, Pontifícia Universidade Católica do Rio de Janeiro, Rio de Janeiro, 2006.

DEBORD, Guy. A sociedade do espetáculo. Rio de Janeiro: Contraponto, 1997.

DURKHEIM, Émile. O suicídio. São Paulo: Martins Fontes, 2000.

FERREIRA, Elisabete Zimmer; OLIVEIRA, Adriane Maria Netto de; MEDEIROS, Silvana Possani; GOMES, Giovana Calcagno; CEZAR-VAZ, Marta Regina; ÁVILA, Janaína Amorim 
de. A influência da Internet na saúde biopsicossocial do adolescente: revisão integrativa. Revista Brasileira de Enfermagem, Brasília, v. 73, n. 2, 2020.

GUIMARÃES, Joana Maria Vieira Robalo Ferreira de Almeida. Suicídio mítico: uma luz sobre a antiguidade clássica. 2010. Dissertação (Mestrado em Estudos Clássicos-Mundo Antigo, Faculdade de Letras) - Centro de Estudos Clássicos e Humanísticos, Universidade de Coimbra, 2010.

KAMPER, Dietmar. O padecimento dos olhos. In: CASTRO, Gustavo de; CARVALHO, Edgard de Assis; ALMEIDA, Maria da Conceição de (org.). Ensaios de complexidade. Porto Alegre: Sulina, 1997. p. 131-137.

KATO, Takahiro A.; SHINFUKU, Naotaka; TATENO, Masaru. Internet society, Internet addiction, and pathological social withdrawal: the chicken and egg dilemma for Internet addiction and hikikomori. Current opinion in psychiatry, v. 33, n. 3, p. 264-270, 2020.

KEMP, Simon. Digital 2020: July Global Statshot. Datareportal. 21 July 2020. Disponível em: https://datareportal.com/reports/digital-2020-july-global-statshot. Acesso em: 28 dez. 2020.

LE BRETON, David. Adeus ao corpo. Papirus Editora, 2003.

LEPORACE, Gustavo; METSAVAHT, Leonardo; DE MELLO SPOSITO, Maria Matilde. Importância do treinamento da propriocepção e do controle motor na reabilitação após lesões músculo-esqueléticas. Acta fisiátrica, São Paulo, v. 16, n. 3, p. 126-131, 2009.

LIN, I-Hsuan; KO, Chih-Hung; CHANG, Yu-Ping; LIU, Tai-Ling; WANG, Peng-Wei; LIN, Huang-Chi; HUANG, Mei-Feng; YEH, Yi-Chun; CHOU, Wen-Jiun; YEN, Cheng-Fang. The association between suicidality and Internet addiction and activities in Taiwanese adolescents. Comprehensive psychiatry, v. 55, n. 3, p. 504-510, 2014.

MELEIRO, Alexandrina Maria Augusto da Silva; MELlO-SANTOS, Carolina de; WANG, Yuan-Pang. In: LOUZÃ NETO, Mario Rodrigues; ELKIS, Hélio. Psiquiatria básica. 2. ed. Porto Alegre: Artmed, 2007. p. 475-496.

MINOIS, Georges. História do suicídio: a sociedade ocidental diante da morte voluntária. São Paulo: Editora Unesp, 2018. 
MORIN, Edgar. Cultura de massas no século XX - neurose e necrose. 11. ed. São Paulo: Forense Universitária, 2018. v. 1.

ORGANIZAÇÃO MUNDIAL DA SAÚDE (OMS). Prevenção do suicídio: um manual para profissionais da mídia. Genebra, 2000. Disponível em: https://www.who.int/mental_health/prevention/suicide/en/suicideprev_media_port.pdf. Acesso em: 7 set. 2020 .

ORTIZ, Patricia; KHIN KHIN, Eindra. Traditional and new media's influence on suicidal behavior and contagion. Behavioral sciences \& the law, U.S., v. 36, n. 2, p. 245-256, 2018.

PEREIRA, Camila Corrêa Matias; BOTTI, Nadja Cristianne Lappann. O suicídio na comunicação das redes sociais virtuais: revisão integrativa da literatura. Revista Portuguesa de Enfermagem de Saúde Mental, Porto, n. 17, p. 17-24, jun. 2017.

POPOOLA, Olalekan; OLAGUNDOYE, Olawunmi; ALUGO, Morenike. Social media and suicide. Anxiety Disorders. IntechOpen, London, Sep., 2020. Disponível em https://www.intechopen.com/books/anxiety-disorders-the-new-achievements/social-mediaand-suicide Acesso em: 20 nov. 2020.

RYU, Eun Jung; CHOI, Kwi-Soon; SEO, Jeong-Seok; NAM, Bum-Woo. The relationships of Internet addiction, depression, and suicidal ideation in adolescents. Taehan Kanho Hakhoe Chi, Coréia do Sul, v. 34, n. 1, p. 102-110, 2004.

ROMANO, Vicente. Ecología de la comunicación. Barcelona: Ed. Hiru Argitaletxea, 2004.

SACRAMENTO, Igor. O espetáculo do trauma: narrativas testemunhais de celebridades sobre o bullying num programa de TV. Revista Contracampo, Niterói, v. 35, n. 02, p. 157-182, ago./nov., 2016.

SAMPAIO, Daniel. Ninguém morre sozinho, o adolescente e o suicídio. 13. ed. Lisboa: Caminho, 2002.

SARAMAGO, José. Ensaio sobre a cegueira. Editora Companhia das Letras, 1995. 
SERVA, Leão. Jornalismo e desinformação. São Paulo: Senac, 2019.

SIEBEL, Márcia Teresa; SANTOS, Bruna da Silva; MOREIRA, Líbia Miranda; SANTOS, Viviane Silva. A influência das redes sociais para o suicídio na adolescência. Revista Ciência (In) Cena, Salvador, n. 8, p. 121-133, 2019.

SILVA, Mauricio Ribeiro da; BAITELLO JR., Norval. Vínculos hipnógenos e vínculos culturais nos ambientes da cultura e da comunicação humana. In: ENCONTRO ANUAL DA COMPÓS, 23., 2013, Salvador. Anais [...]. Disponível em: http://compos.org.br/data/biblioteca_1994.pdf. Acesso em: 3 set. 2020.

SUICIDE: one person dies every 40 seconds. World Health Organization (WHO). 9 Sept. 2019. Disponível em: https://www.who.int/news-room/detail/09-09-2019-suicide-one-persondies-every-40-seconds. Acesso em: 10 ago. 2020.

SUICÍDIOS aumentaram nos EUA logo após Robin Williams se matar, mostra levantamento. BBC News Brasil, 8 fev. 2018. Disponível em https://www.bbc.com/portuguese/geral42988493. Acesso em: 15 ago. 2020.

TORRES, Leonardo de Souza Aloi. Contágio psíquico na mídia eletrônica. 2020. Tese (Programa de Pós-Graduação em Comunicação) - Universidade Paulista, São Paulo, 2020.

WORLD HEALTH ORGANIZATION (WHO). Suicide in the world: global health estimates. World Health Organization, Geneva, 2019. Disponível em: https://apps.who.int/iris/bitstream/handle/10665/326948/WHO-MSD-MER-19.3eng.pdf?ua=1. Acesso em: 15 ago. 2020.

Submetido em: 27.09.2020.

Aprovado em: 25.05.2021. 